\title{
MONJAS, ASESINATOS Y APARICIONES. RUMOR Y ALTERIDAD RELIGIOSA EN EL CONTEXTO DE LAS EXPERIENCIAS FORMATIVAS DE LOS NIÑOS Y NIÑAS DE UN BARRIO TOBA/QOM DE BUENOS AIRES
}

\author{
Mariana GARCÍA PALACIOS ${ }^{1}$
}

\section{Resumen}

Entre los niños y niñas de un barrio toba/qom de Buenos Aires circula el rumor de que antes de que arribaran las familias al terreno, las "monjitas" que vivían en la escuela católica a la que ellos asisten enterraron bebés y aún hoy se oye su llanto. Este artículo, por un lado, situará estas apariciones en el marco de las experiencias formativas de los niños en el Evangelio. Por otro, analizará las tensiones entre la escuela y el barrio, profundizando en cómo los rumores abonan la construcción de un "otro".

Palabras clave: Rumor; Alteridad religiosa; Experiencia formativa; Niñez

\begin{abstract}
The children of a Toba/Qom urban setting near Buenos Aires told each-other a rumor: before their families arrived to the land, many babies were buried there by the "monjitas" (little nuns) and up until this days, one can still hear them crying. The nuns lived in the Catholic school where the children study. The aim of this article is to analyze this rumor in two interconnected ways. First, I will consider this appearances regarding several children's formative experiences in the Evangelio. Second, I will focus on the tensions between the Catholic school and the Toba neighborhood, and on the "otherness" constructed by this rumor.
\end{abstract}

Key words: Rumor; Religious otherness; Formative experiences; Childhood

\section{Résumé}

Parmi les enfants d'une agglomération toba/qom de Buenos Aires, le rumeur circule qu'avant l'arrivée des familles, les «monjitas » (les « bonnes sœurs ») qui vivaient dans l'école catholique à laquelle les enfants assistent aujourd'hui avaient enterré des bébés, et qu'il est toujours possible d'entendre leur pleur. D'une part, cet article situera ces apparitions dans le cadre des expériences formatives des enfants dans l'Evangelio. D'une autre, il analysera les tensions qui existent entre l'école et l'agglomération, en

1 Profesora de la Facultad de Filosofía y Letras, Universidad de Buenos Aires (Argentina). Becaria Postdoctoral del Consejo Nacional de Investigaciones Científicas y Técnicas (CONICET). Doctora en Antropología por la Facultad de Filosofía y Letras (Universidad de Buenos Aires). E-mail: mariana.garciapalacios@gmail.com

Fecha de recepción del artículo: Noviembre 2014

Fecha de evaluación: Mayo 2015 
approfondissant sur la manière dont les rumeurs contribuent à la construction d'un « autre ».

Mots-clés: Rumeur; Altérité religieuse; Expériences formatives; Enfants

\section{1) Presentación}

Según Hirschfeld, "Los niños son criaturas valiosas en prácticamente todas las sociedades. Se reconocen prácticas de cuidado y sustento peculiares (...) En todos lados $\mathrm{y}$ en todos los tiempos, las personas tienen ciertas creencias acerca de lo que los niños son y qué debe 'hacerse' con ellos" (2002: 613-614, traducción propia). No obstante, mientras que aparentemente en todas las configuraciones socioculturales se han otorgado significaciones particulares a diferentes "edades de la vida", este contenido varía muy significativamente (Stephens, 1995). Como en este artículo nos proponemos analizar las experiencias formativas de los niños y niñas de un barrio toba/qom de Gran Buenos Aires ${ }^{2}$, haciendo hincapié en el lugar del rumor y la alteridad religiosa en ellas, será necesario comprender primeramente los diversos modos en que se concibe y subdivide la niñez en los grupos tobas, y las disputas de sentido en este campo.

Retomando los estudios realizados por Hecht (2010), en los que la autora parte de las categorías lingüísticas de clasificación del ciclo de vida, podemos conocer que en la lengua toba existe un término cuya traducción sería equivalente a "la niñez y la juventud": nogotshaxac (nogot significa "niño/joven" y shaxac "la manera de ser"; literalmente, entonces, "la manera de ser niño/a/joven"). Este período abarca desde el nacimiento hasta la llegada del primer hijo/a. Comprende, a su vez, distintas etapas, evidenciadas en el uso de las categorías que las denominan, que implican actitudes, habilidades y características diferenciales esperadas. Es interesante señalar que como cada etapa no sólo aparece demarcada por una denominación particular, sino por un estatus y un rol esperado, y por cambios percibidos como significativos, aún cuando en el contexto del barrio en Buenos Aires muchas de las categorías lingüísticas han caído en desuso, es posible hablar de cierta continuidad en la forma de concebir el crecimiento de las personas (Hecht, 2010).

La primera de las etapas dentro de la nogotshaxac ("la manera de ser niño/a/joven") comprende al período de gestación intrauterina: el niño/a es mencionado como huete'o, en los primeros meses, y hueta'o en los siguientes. Tola (2007), interesada en el análisis de la concepción del cuerpo y de la persona entre los qom de Formosa, nos presenta elementos acerca de esta etapa. Según la autora, las personas existen potencialmente en el cielo como lqui' $i$, antes de descender al vientre y comenzar su transformación en un cuerpo humano. Según la autora, es importante no confundir la idea de lqui'i con la de

2 Los llamados "barrios tobas" comenzaron a constituirse en distintos pueblos y ciudades de la provincia de Chaco a fines de los años ' 50 del siglo XX, y en Formosa desde la década del '70 (Wright, 1999; Bartolomé, 1971). Luego de procesos migratorios desde la región chaqueña, se conformaron otros barrios en centros urbanos, y sus alrededores, principalmente en Rosario (Bigot, Rodríguez y Vázquez, 1992), La Plata (Tamagno, 2001) y Buenos Aires. El barrio al que se hace referencia fue construido en la década del '90 por treinta y dos familias, provenientes originariamente de comunidades tobas rurales y semiurbanas de las provincias del Chaco y Formosa (Noreste de Argentina). El terreno pertenecía anteriormente a la Congregación católica que dirige la escuela que se encuentra frente al barrio. Las fuentes de subsistencia principales de las familias consisten en la producción y venta de artesanías; las charlas en escuelas para la venta de artesanías; los trabajos esporádicos en relación de dependencia ("changas", trabajos de albañilería, etc.); y los planes y subsidios del Estado. 
alma, ya que existen en el cielo las lqui'i de niños potenciales y, a su vez, no es una propiedad exclusiva de los seres humanos, sino que muchos otros entes poseen un lqui' $i$ que les da vida, les permite el movimiento y les confiere una imagen. "Aún cuando actualmente la idea de una participación divina en la atribución del componente que posibilita la vitalidad del bebé en gestación está muy diseminada debido a la influencia evangélica desde los años '40, esta idea no entra en contradicción con aquella según la cual padre y madre son los encargados, durante la gestación, de dar al niño su lqui 'i, entendido como apariencia física" (Tola, 2007: 506, traducción propia). Es por ello que se necesita mantener relaciones sexuales constantes los primeros meses de gestación para que los fluidos corporales masculinos y femeninos posibiliten la formación del bebé (Tola, 1999).

Con el nacimiento, la persona es considerada 'o'o' (bebé) hasta la llegada del habla. Cuando el bebé comienza a hablar, se considera que ha ingresado en la siguiente etapa: nogotole/c (niña/niño). El paso a la etapa siguiente está marcado por la primera menstruación (menarca) en el caso de las niñas y por el cambio en la voz en el caso de los varones. Las primeras pasan a ser qañole (jovencita) y los segundos nsoqolec (jovencito), y se considera que ambos ya están listos para independizarse. Esta etapa y todo el período nogotshaxac de la vida culminan con el nacimiento del primer/a hijo/a (Hecht, 2010).

En el barrio de Buenos Aires, los niños y niñas prácticamente desde que pueden caminar con soltura, juegan y circulan sin compañía de los adultos, generalmente acompañados por otros niños/as. Podría considerarse que tienen una autonomía y un margen de decisión mayor a los que se observa en otros grupos sociales, aunque es necesario señalar en que no viven en el barrio aislados y que los adultos están presentes en sus vidas. No se trata de una "falta de cuidado" sino de un fuerte andamiaje grupal y familiar que les da tanto libertad como seguridad de movimientos (Hecht, 2010; Colangelo, 2009). Es más, podría sostenerse que esta relativa autonomía forma parte de una "pedagogía nativa" (Tassinari, 2007) que, habilitándolos a circular por los diversos espacios del barrio y "verlo todo", reconoce su agencia en el aprendizaje. De hecho, esta posibilidad de circulación que los niños y niñas tienen, se pierde a medida que van creciendo: los adultos, en la mayoría de los casos, no entran en una casa sin que medie una invitación a hacerlo y reconocen diferenciaciones entre casas (e hileras) de familiares más directos o más distantes en el barrio.

Como parte de esta circulación, los niños y niñas participan de diversas actividades en las que se relacionan con dos corpus religiosos. Por un lado, en las prácticas sociales que se dan dentro del barrio, se vinculan con las concepciones del Evangelio, movimiento religioso al que adscriben mayoritariamente las comunidades qom y que en el barrio está representado por dos iglesias presididas por pastores tobas: la Iglesia de Jesucristo Pentecostés y la Iglesia Unida. El Evangelio articula elementos propios del evangelismo pentecostal -las nociones pentecostales sobre la sanación y los dones del espíritu, la glosolalia o "don de lenguas"- con el "bagaje sociorreligioso tradicional toba" (Miller, 1979; Wright, 2008; Ceriani Cernadas y Citro, 2005). Por otro lado, la escuela a la que la mayoría de los niños y niñas asistió o asiste pertenece a una Congregación de la Iglesia Católica. Aquí, los niños del barrio representan un porcentaje relativamente bajo de la matrícula general.

Al poder "ver todo", los niños y niñas suelen ser enviados por los adultos a observar algún suceso (una visita en otra casa, la llegada de vehículos, etc.) o a llevar y traer mensajes, y son, de este modo, considerados excelentes "portadores de información". Se 
reconoce también su capacidad para circular rumores, ya que rápidamente "se los cuentan entre ellos" (Pedro, 72 años). Aquí, me interesa referirme a un rumor en particular:

"Las monjas acá cuando no había nadie, estaba solamente la escuela, asi dicen, que acá debajo de la tierra ponen los hijos vivos de las monjas. Y un día había un bebé en la casa de Abril que siempre lloraba a la noche, donde está el pozo... Ahi siempre escuchaban llorar un bebé. Y yo fui un día a la casa de ella a dormir y sí, era verdad" (Malena, 10 años)

"Azucena: Antes, dijeron que acá era un cementerio de las monjas. Cuando mi mamá y mi papá durmieron en la escuela [al llegar al terreno, mientras se construían las casas] se escuchaba de todo, porque todo esto, todo lo del barrio era todo un cementerio. Y encima están enterrados bebés ahogados porque las monjas no pueden tener hijos y a los maridos los ahorcaban y los enterraban

Clarisa: Mi hermana cuando estaba en la escuela dijo que en el baño ella vio una chica muerta

Julieta: cuando yo iba a esa escuela en preescolar, yo no quería ir más a esa escuela porque me daba miedo (...) porque yo tenía miedo porque mi mamá me contó a mí que había monjas que mataban...

Manuela: Yo voy a esa escuela; yo voy a esa escuela con la Martina

Azucena: (...) Algunas monjas venían de otro lado, unas chicas, y cuando quedaban embarazadas, las monjas le hacian abortar el bebé y a los hombres los ahorcan

Clara: En mi casa se escucha un bebé que estaba llorando y después se escuchaba que pateaban

Martina: Ahora hay monjas que son buenitas

Manuela: Son buenas [las monjas]" (Azucena, 11 años; Clarisa, 9 años; Julieta, 10 años; Martina, 8 años; Manuela, 5 años; y Clara, 9 años)

"Javier: Dicen que murió un bebé ahí.

Camilo: O si no, dicen que allá en la casa de la Mirta que hay un coso así grandote... que habia una pileta... esa piscina era de las monjas y dicen que... todavía no estaba el barrio... y dicen que las monjas tiraban todos los cuerpos de otras monjas ahí.

Javier: y esas monjas están por ahi ¿viste en aquella casa? (...) Ellos me contaron que siempre veían una monjita, una que falleció. Y ellos siempre la veían, siempre estaba parada así, a la noche (...)

Camilo: Y... son espíritus que andan por la noche...

Javier: que merodean...

Camilo: como los lobizones que andan a la noche por ahí..." (Javier y Camilo, 13 años)

Para el análisis de este rumor que involucra a las religiosas de la escuela, se desarrollarán dos líneas de indagación. Por un lado, se situarán estas apariciones que se dan en el barrio (junto con otras, como la del lobizón que se menciona arriba en uno de los fragmentos, el pomberito, el duende y distintos "fantasmas") en el marco de las experiencias formativas religiosas de los niños y niñas en el Evangelio. Por otro lado, se tendrá en cuenta las diversas tensiones entre los representantes de la institución escolar católica y los habitantes del barrio. Aquí, la religión deviene un terreno fértil 
para estas confrontaciones y, en este sentido, considero interesante analizar cómo los rumores abonan la construcción de un "otro", y cómo este mecanismo forma parte también de las experiencias formativas de los niños y niñas.

\section{2) Las apariciones y la oración como experiencias formativas en el Evangelio}

Mencionábamos que durante la niñez las personas poseen un amplio margen de "circulación" por diversas experiencias formativas ${ }^{3}$. Con respecto a esto, es importante señalar, en principio, que puede observarse en esta "pedagogía nativa", la concepción del aprendizaje a través de la circulación y la participación activa y vivencial. Veamos esta dimensión vinculada al conocimiento construido sobre las apariciones en el barrio:

"Luego de que Noelia narrara con gran detalle lo que le habian contado sobre la aparición del lobizón, le pregunto si 'hacen algo' los lobizones y ella me responde 'No sé, a mí nunca me apareció'”, (Noelia, 13 años).

"Pero...de eso, de enanitos, fantasmas y todo eso... sí, suponete que sí, voy a creer cuando vea o me pase a mi" (Renata, 16 años).

Esta importancia dada a lo vivencial como parte del aprendizaje suele ser destacada entre los adultos del barrio, que suelen afirmar con respecto a diversos temas "yo lo sé porque lo viví, no me lo contaron como a ustedes en los libros" (Pedro, 68 años). A su vez, implica un posicionamiento con respecto a los niños y niñas del barrio, ya que para muchos adultos, ellos no conocen gran parte de estas cuestiones (sobre todo las que se consideran vinculadas con el conocimiento monte) porque siempre "vivieron en la ciudad".

Por otro lado, otro rasgo importante de la "pedagogía nativa" implica la concepción de que cuando la persona atraviesa la niñez, no debe dar cuenta necesariamente de los conocimientos que sí se esperan en la adultez (hablar la idioma, conocer el Evangelio, saber hacer artesanías, etc.). Así, para los habitantes del barrio pareciera no resultar contradictorio que, hasta la llegada de la adultez, las personas circulen y participen de los distintos espacios y se vinculen con diferentes conocimientos religiosos. Esto otorga, a su vez, a los niños cierto carácter de mediadores. Por ejemplo, pese a que los niños no son ajenos a las tensiones y conflictos que existen entre las dos iglesias del barrio, también suelen mediar entre ellas. Muchos van indistintamente a los dos cultos o bien van al culto de la Unida y luego a la Pentecostés a la "escuelita dominical".

En este sentido, y a diferencia de lo que suele suceder en muchos otros grupos sociales en los que las personas que se consideran a sí mismas como parte de una religión no permiten que sus hijos realicen los rituales de otra religión, en el barrio no resulta problemático que los niños y niñas posean diversas experiencias formativas religiosas durante su niñez. En una entrevista, uno de los ancianos del barrio, segundo pastor de la Iglesia Unida, comentó con respecto a la asistencia de su nieta a las clases de religión en la escuela católica: "tienen que aprender todo lo que puedan aprender (...) Después,

3 Dentro del campo de la antropología de la educación, se ha incorporado la idea de apropiación como contrapeso al concepto de socialización, desarrollando la noción de experiencia formativa en referencia al conjunto de relaciones y prácticas cotidianas (escolares, familiares, barriales, etc.) en las que los niños y niñas se involucran activamente y que condicionan, en tanto limitan o posibilitan, el sentido de sus diferentes construcciones (Rockwell, 1995; Achilli, 1996). 
de grandes, ven dónde se ubican" (Benjamín, 78 años). Del mismo modo, Blanca, de 35 años, nos contó que cuando su hija Sofía a los 10 años le dijo que quería tomar la comunión con los compañeros de escuela católica, a ella le pareció que si la nena quería estaba bien. Lo curioso es que sostuvo que ella misma no participaba en un grupo de meditación que concurría al barrio ya que prefería "no mezclar" porque ya estaba con el Evangelio.

Teniendo en cuenta que las personas, en sus distintas experiencias, se apropian activamente de significados culturales previos, considero que es justamente la participación en las distintas experiencias formativas cotidianas lo que contribuye con el proceso mismo de construcción de las creencias religiosas (Toren, 2003; García Palacios, 2012). En este punto, me interesa situar las apariciones en el barrio en el marco de las diversas experiencias formativas religiosas de los niños en el Evangelio.

Actualmente, en la Iglesia de Jesucristo Pentecostés se llevan a cabo, por períodos, encuentros semanales de la "escuela dominical" (especialmente destinados a los niños y niñas), $\mathrm{y}$, en ambas iglesias, se realizan los cultos. Ir a la iglesia forma parte de la cotidianeidad de niños y adultos en el barrio, pero también existen otros medios por los que los niños se vinculan con el Evangelio, como la música que suena en el barrio o los videos que circulan en distintas casas y que difunden mensajes evangélicos. Por otro lado, en tanto la Biblia constituye la apelación final de autoridad (Miller, 1979), hasta niños y niñas muy pequeños pueden poseen su propia Biblia. Por último, las oraciones suelen ser una práctica de lo más usual, y esto por varias razones. Puede ocurrir que las personas vayan a la iglesia o pasen por las casas si alguien necesita que "le oren" por una dificultad particular:

"Cuando te hacen brujería, tenés que ir a la iglesia y pedir oración” (Azucena, 11 años)

"Mariana: ¿Qué más hacen en las iglesias?

Julieta: Cantamos, oramos y...

Clarisa: Y siempre, siempre

Francisco: Oraciones para los que están enfermos

Julieta: Oramos por los que están en las cárceles, en los hospitales... Hacemos....todo eso (...) Yo pedía peticiones por ella [Clarisa] porque [estaba enferma]

Mariana: ¿Si? ¿Qué pasó?

Julieta: Estaba en el hospital (...) ¿Y viste lo que te dije? (...) Se cumplió, porque pasaban casa por casa a pedir petición y mi padrastro también, pidió una petición, casa por casa pasaban y....después le oraban. Le oraban y así se fue cumpliendo" (Julieta y Francisco, 10 años, y Clarisa, 9 años)

En estos fragmentos, puede verse el fuerte énfasis en la curación que se mantiene en el Evangelio y cómo los chicos participan de estas experiencias y construyen su conocimiento sobre las potencialidades de la oración ${ }^{4}$. Por otro lado, los niños y niñas comentan que oran cuando sienten miedo y muchas veces, este miedo se encuentra asociado a las apariciones de seres en el barrio.

\footnotetext{
$4 \quad$ Cabe señalar que los aspectos terapéuticos del culto impregnan, en combinación con otros recursos, las formas de atención y cuidado de los niños desde el nacimiento (Colangelo, 2009). Estas pautas se articulan (no sin conflictos) con la atención médica y con algunas "creencias de los antiguos".
} 
Pires (2007), en una investigación en Catingueira, Brasil, también analiza las ideas de los niños acerca de los "malos-assombros". Según la autora, a medida que los niños crecen, se da un proceso de "cristianización" de las apariciones que consistiría tanto en una reducción de su variedad a un único tipo, las almas de los muertos, como en la consideración de que esas son cosas de Dios o del demonio. En el barrio, considero que el primero de los procesos señalados no es algo que suceda necesariamente ya que puede sostenerse en términos generales que los adultos postulan la existencia de diversos seres no humanos, aunque hay una alta variabilidad en lo que pude registrar. Para algunos adultos, como Pedro (72 años), el pomberito, el duende y el lobizón "existen, pero sólo en el Chaco, no en el barrio", si bien según una niña de 10 años, "En el bajo hay un lobizón, es buenito, no es malo, ya todos los vecinos le vieron. Hay un lobizón pero nadie sabe quién es. Benjamín [anciano del barrio] sabe quién es, pero no dice quién es". En este sentido, con la edad no pareciera haber necesariamente una reducción en la variedad de apariciones que se reconocen, pero sí hay una reinterpretación de estos seres, una vez que la persona se ha "entregado al Evangelio", Veamos el siguiente fragmento:

"Esas cosas no son cosas buenas. Si vos creés y tenés la luz por creer en el Evangelio, esas cosas no te aparecen. Lo de los fantasmas no es así porque las almas, la Biblia dice que cuando una persona muere, el alma se hace como un polvito y se va. O sea, no puede ser que se quede donde muere; eso no es asi"' (Eduardo, 52 años)

En lo dicho por Eduardo, se hace referencia a una concepción particular acerca de lo que sucede a partir de la muerte. Diversos autores han dado cuenta de la diversidad de creencias y actitudes frente a la muerte, tanto en las diferentes culturas como dentro de una misma cultura en diferentes períodos históricos (Thomas, 1991; Barley, 2000). Para el caso de los grupos tobas, Tola (2006) señala que según la concepción tradicional, desde el momento de la muerte “... y durante un tiempo variable el lqui' $i$ ronda por la tierra, permaneciendo cerca de su familia y de su cuerpo enterrado" (155). Esta idea se modificó en parte por la introducción del Evangelio (como se evidencia en el fragmento). No obstante, observemos los siguientes registros:

"Pedro y sus hijos, Ciro y Liliana, están charlando acerca de qué pasa si es el juicio final y alguien no está entregado al Evangelio. Pedro dice que queda como fantasma en la tierra, porque si no ¿cómo se explicaría la existencia de los fantasmas? Ciro y Liliana gritan 'ino existen!': al morir se va al cielo o al infierno. Comienzan entonces a discutir. Pedro dice que existen los fantasmas; Ciro y Liliana que no (ellos dos 'están en el Evangelio')" (Pedro, 71 años; Liliana, 31 años y Ciro, 22 años)

"Es una sombra [en referencia a una chica que aparece cerca de la zona del centro comunitario]. Ahí vive, ahi está el espiritu (...) Porque el cuerpo está enterrado por acá, porque esto antes era un cementerio de las monjas" (Julieta, 9 años)

"Mi papá y todos los hermanos oraban porque la nena [que falleció en el barrio] se vaya, para que esté bien y para que se vaya con Dios. Y estaban ahi y las hermanas cantaban con la Érica, las hermanas que van a la iglesia" (Andrea, 11 años)

\footnotetext{
5 "Entregarse" es una expresión nativa que señala que la persona "deja las cosas del mundo" (la
} bebida, el tabaco, el adulterio, la "joda", etc.) y comienza a "estar en el Evangelio". 
Como puede verse en los fragmentos anteriores, no existe un consenso generalizado acerca de las "creencias de los antiguos" (incluso en una misma persona en diferentes contextos de prácticas). Las posiciones de las personas del barrio que adscriben al Evangelio con respecto a los "elementos tradicionales nativos" no son unívocas algunos consideran que el Evangelio ha "civilizado" muchas de las tradiciones y "creencias de los antiguos", mientras que otros reivindican éstas últimas por sobre las propuestas por el pentecostalismo -como señala Citro (2009) para el caso de Formosa. Pese a estos desacuerdos, sí pareciera haber un gran consenso en cuanto a que siempre es posible (y deseable) orar ante casos de una aparición. Incluso, es posible bautizarse, como sostienen muchos niños y niñas: "A mi antes me aparecían cosas, al Ale, todo, pero desde que nos bautizamos no nos apareció más" (Marina, 12 años). Así, los niños y niñas aprenden desde muy pequeños que hay que orar cuando se tiene miedo, tal como me contaba Tamara, de 5 años: según ella, cuando su hermanito, de 2 años, tiene miedo, "hay que orar fuerte para que no tenga miedo. O si no juego [con él]". Sus palabras muestran un conocimiento del acto de orar y sus potencialidades, así como que éste para los niños más pequeños, no está necesariamente separado del ámbito de lo cotidiano (para que se vaya el miedo también se puede jugar).

En definitiva, las apariciones en el barrio forman parte de las experiencias formativas a partir de las cuales los niños y niñas construyen conocimientos religiosos acerca del Evangelio, como se evidencia en el caso de la oración.

\section{3) Las iglesias del Evangelio y la escuela católica: el rumor ante la alteridad religiosa}

La producción y circulación de rumores resultan prácticas que lejos de ser un obstáculo para las relaciones comunitarias, forman parte del proceso a través del cual los actores otorgan significación y constituyen la vida social (Fasano, 2006). Siguiendo a Ceriani Cernadas (2008), podemos sostener que el mundo de los rumores resulta un campo fecundo para explorar los procesos de construcción de la otredad social. Para el autor, "Las situaciones de contacto y cambio cultural se sitúan igualmente como terrenos fértiles para el rumor, el chisme y la acusación" (246). En este sentido, una breve revisión histórica de los vínculos entre los grupos tobas, el Evangelio y la Iglesia católica, nos permitirá dar cuenta de la potencialidad del rumor para construir la comunidad del "nosotros" al alterizar a otro grupo, al que se contrapone.

El proceso de sociogénesis del Evangelio en el Gran Chaco se debe a diversas experiencias históricas regionales, que incluyen diversos conflictos y divergencias. Aquí hay que contemplar iniciativas más bien individuales, el ingreso de las iglesias anglicanas, el asentamiento de iglesias pentecostales en la zona, algunos movimientos religiosos liderados por aborígenes y la labor de misioneros menonitas norteamericanos, que inicialmente establecieron una misión en Chaco y luego permanecieron en calidad de "asesores" u "obreros fraternales" (Wright, 2008; Ceriani Cernadas y Citro, 2005; Citro, 2009).

Con el propósito de analizar por qué el Evangelio se constituyó y se presenta como "la religión de los tobas" (aun cuando las interpretaciones de sus sentidos no sean homogéneas), resulta de interés recurrir a los estudios de Segato $(2007,2005)$ que en su investigación sobre la expansión del evangelismo en el noroeste de Argentina da cuenta de un proceso de re-simbolización de la contradicción entre la etnia y el Estado-nación. 
Esta oposición ha sido históricamente clave en la lucha y reafirmación étnica de los grupos indígenas del país. Si bien la Argentina es considerada un país laico (según la Constitución Nacional, art. 14, todos/as los/as habitantes de la Nación gozan del derecho de profesar libremente su culto), el Gobierno Federal de la Nación sostiene el culto católico (art. $2^{\circ}$, Constitución Nacional). La religión católica aparecería en la Argentina como una "religión privilegiada", quedando "desmarcada" (Wright, 1999). La dinámica de desmarcación invisibiliza la especificidad del catolicismo, mostrándolo como la religión "universal", al acentuar la especificidad de las demás religiones. Las religiones evangélicas proporcionarían, así, nuevas formas para plasmar la oposición de los grupos étnicos, que ahora se presentaría como la oposición entre evangelismo y catolicismo. Esto cobra aún más sentido si tenemos en cuenta el contacto con misioneros católicos de los grupos indígenas de Gran Chaco. Según Wright, los tobas recuerdan "el tiempo de los curas" como una estancia diseñada por el gobierno para "civilizar y domesticar la cultura aborigen" (2008:161), lo cual para el autor, mostró al pentecostalismo como "liberador", "pero al costo de la estigmatización de sus prácticas ancestrales", en muchos casos (en Ceriani Cernadas, 2008:205).

El Evangelio representó para los grupos tobas una posibilidad doble: por un lado, la posibilidad de incorporar ciertos rasgos culturales doqshi (blancos) y por otro, dar continuar, aunque no sin conflictos, a elementos de las creencias y prácticas rituales propias (Ceriani Cernadas y Citro, 2005). La importancia relativa que se da a estos elementos genera ciertas diferencias y tensiones entre las dos iglesias del barrio. Sin embargo, simultáneamente, y ante la otredad que se construye sobre el catolicismo, consideran que "igual seguimos siendo hermanos de Cristo" (Alba, 14 años); "es lo mismo, la Biblia es la misma, sólo cambian los nombres" (Estrella, 34 años).

Teniendo en cuenta lo desarrollado hasta aquí, la presencia de la escuela católica en la vida de los habitantes del barrio reasegura a la religión en tanto marcador étnico: allí puede escucharse "los tobas tienen otra religión, otro pensamiento", "no son católicos", "son evangelistas". La Congregación que está a cargo de la institución escolar fue fundada en 1866 en Italia. En 1913, las Hermanas arriban a la Argentina para pronto instalar en un "rancherio del Bajo Belgrano", en Buenos Aires, un colegio gratuito para niñas "con el objeto de fijarles una mejor dirección en la vida" (Recuerdos, 1980: 1). En el actual edificio de Gran Buenos Aires (antigua casa de vacaciones de seminaristas), se estableció en 1942 una colonia de vacaciones para niñas de centros catequísticos parroquiales de la Arquidiócesis de Buenos Aires. En 1944, se alojaron treinta niñas sanjuaninas que habían sufrido las consecuencias de un terremoto, a las que se sumaron luego otras niñas, lo que dio inicio a un internado. Recién en 1960 se crea la escuela primaria actual y con los años el régimen de internado desaparece gradualmente.

En la escuela, todos los alumnos asisten semanalmente, desde el nivel inicial, a clases de catecismo de aprobación obligatoria. También participan de las actividades rituales que acompañan la escolarización: diariamente se reza en las aulas y en la formación al iniciar y concluir cada día, se realizan convivencias, misas, etc. Por otro lado, el espacio aparece colmado de carteles y símbolos religiosos: estatuillas y cuadros de Jesús, de la Virgen y de las hermanas de la Congregación, cruces en lo alto de los pizarrones de cada aula, carteles con anuncios del calendario litúrgico, etc. Como mencionábamos, en el caso de los niños y niñas del barrio, la contraposición existente entre Evangelio y Catolicismo puede ser observada en una escala más cotidiana en relación con esta escuela a la que asisten o asistieron. Aquí se los identifica en primera instancia como "no católicos": 
"a los únicos chicos que dejamos entrar que no sean católicos son los tobas" (Ernesto, vicedirector).

“... vos firmás el contrato e ingresás al colegio. En el contrato está estipulado [que los niños deben tomar la Primera Comunión en $5^{\circ}$ grado]. [En el caso de los chicos del barrio] los padres optaron por otra religión, pero se les da la oportunidad de que sigan porque tienen la escuela enfrente. Para no crearles tampoco un trastorno a ellos de que los tengan que mandar a otra escuela. Es un poco también tiene que ver con la caridad de la escuela y de la Iglesia, ¿viste?, no excluir. No excluir, con ellos se hace eso, tienen ese ¿cómo es que se dice?... Ese privilegio, por decirlo de alguna manera, con ellos, pero nada más" (Marcos, catequista sacramental)

Es interesante la mención a la caridad en este último fragmento, ya que es uno de los pilares de la Congregación: el encabezado de su Reglamento es "El principal objetivo de este Instituto es practicar la caridad" (1991: 21) ${ }^{6}$. En efecto, en el ideario de la escuela se establece que uno de sus "Fundamentos carismáticos" es la "Donación materna": "El amor a Dios y a los hermanos impulsa a una entrega desinteresada, reflejo del amor misericordioso de Dios y de la misión materna de la Santa Madre" (Ideario: 2$)^{7}$. De este modo, la inclusión de los chicos en el establecimiento se concibe como un acto caritativo de parte de la escuela y esto hace inteligible muchas de sus acciones y su relación con el "barrio toba" y los barrios vecinos.

La Iglesia católica nunca estuvo ausente en el disputado campo de la "asistencia" y la "cuestión social" en el país, presentándose siempre como el reverso, en materia de asistencia, promoción o política social de lo que Estado hacía o no hacía (Zapata, 2005). En 1980, en los Recuerdos de la escuela, escribían acerca de los barrios circundantes:

"Los alrededores cambiaron radicalmente. Se instalaron barrios de emergencia y hoy existe una población inmensa, casi en su totalidad muy pobre (...) La obra social en el barrio, consuelo, asesoramiento, asistencia a los enfermos e invitación a llevar una vida auténticamente cristiana, va creciendo con la población” (Recuerdos, 1980: 91).

Como señala Santillán (2009), en una coyuntura social fuertemente marcada por un crecimiento de la marginalidad y una fragmentación heredada del período dictatorial, la Iglesia se constituye como una presencia casi exclusiva a nivel institucional. En la década de los '90 y en un contexto signado por la "crisis del Estado de Bienestar" y un creciente proceso de privatización, la Iglesia interviene de forma ininterrumpida en los conflictos sociales y políticos (Santillán, 2009). Reinterpretando en términos morales el debate entre las incumbencias públicas y privadas, la caridad aparece como un modo católico de subsanar problemas de índole estatal. De este modo, con otro lenguaje, la Iglesia se reposiciona y disputa un lugar en el campo de la política social (Zapata,

\footnotetext{
$6 \quad$ La caridad es una de las tres virtudes teologales sostenida por la Iglesia Católica (además de la fe y la esperanza) que caracterizarían el obrar cristiano. Según Zapata (2005), en la década de 1950, con una intención de renovación, la categoría de beneficencia entra en desuso y se recrea el significado de la vieja categoría teologal de la caridad.

Muchos docentes y directivos se apropian de este lenguaje y utilizan en la descripción de su labor, expresiones como "sembrar amor", "Dios me mandó acá, yo sé que fue Dios soy muy creyente", "Tengo vocación de servicio", "Es un poco devolver todo lo que Dios te da".
} 
2005). En este marco, a mediados de los '90, se conforma el barrio. Según la asistente social de la escuela, quien se desempeñó en el cargo de 1993 a 2011,

"Bueno, se hizo el contacto con la curia, les regalaron los terrenos, se consiguió también por una fundación que les donaran los materiales y ellos se construyeron las viviendas. Entonces la curia les cedió todos los terrenos a la congregación nuestra y pudieron regalarle los terrenos que restan más adelante, que es el barrio (da su nombre), porque la gente que vivía acá en los barrios se empezó a sentir mal, dicen ¿cómo viene gente de afuera, nosotros viviendo acá -algunos en unos ranchitos, pobrecitos, lamentables, gente muy pobre habia-. Bueno, primero dijeron que eran evangélicos. Entonces la escuela les permitió igual venir, que antes no se hacía porque había una familia evangélica acá en el barrio, que la señora es una señora uruguaya, que son evangélicos y cuando vieron que ya los chicos no iban a recibir la catequesis acá en la escuela, les dijeron que ya no podían recibirlos más y a esta gente sí, no les podian decir que no, ¿viste?"

(Norma, Asistente social)

Mientras que para los habitantes del barrio las tierras representan la confluencia de diversas experiencias y acciones colectivas de lucha, organizadas en pos de la demanda por el cumplimiento de un derecho (Spennemann, 2006), en las posiciones construidas desde la escuela (hermanas de la congregación, docentes y profesionales del gabinete), las tierras aparecen mayoritariamente como un "don" otorgado. En este mismo sentido, desde la congregación se afirma haber distribuido y donado diversos bienes y recursos que van desde las tierras, albergue en la escuela para las primeras personas que llegaron al barrio (mientras construían las primeras casillas), donaciones de ropa, ayuda con los trámites de documentaciones y con la solicitud y distribución de planes y subsidios del Estado. La misma asistente social sostiene que

"Se los ayudó mucho en todo, en todo, en todo, en orientación, en cosas materiales, tienen la salita acá [de primeros auxilios, el edificio es de la congregación, pero los profesionales dependen del municipio]. Hicimos los trámites para que hicieran el cambio de domicilio..." (Norma, Asistente social).

Las personas que hacen caridad, como señala Zapata (2005) no pretenden a cambio bienes tangibles. Están orientadas hacia otros bienes: “... su recompensa, no consciente ni plenamente buscada y calculada, la encuentran en las formas de autoridad que se inscriben en las personas" (51). Es por ello que se espera cierto estado de agradecimiento que se convierte en una obligación perdurable ${ }^{8}$, que es necesario enunciar/denunciar en "documentos institucionales" aún muchos años después:

"Tanto las familias de la comunidad Toba como las del nuevo barrio (...) están sumamente agradecidas por tener la posibilidad de vivir con mayor protección, seguridad y dignidad" (Diagnóstico situacional, Año 2008)

$8 \quad$ Bourdieu (2010) sostiene que “... no hay más que dos maneras de tener a alguien de manera perdurable: el don o la deuda, las obligaciones abiertamente económicas que impone el usurero, o las obligaciones morales y los apegos afectivos que crea y mantiene el don generoso, en una palabra la violencia abierta o la violencia simbólica, violencia censurada y eufemizada, es decir irreconocible y reconocida" (202-203, subrayado en el original) 
La propia enunciación de este "deber ser", denuncia la eventual falta de agradecimiento $\mathrm{y}$, en este sentido, la ausencia de una respuesta que no cubra con las expectativas de quienes están en la posición de dar puede ser interpretada como desagradecimiento:

"Los tobas son desagradecidos, porque insisten en el tema de la discriminación con todo lo que se los ha ayudado" (Ernesto, vicedirector)

"Lo que pasa es que ellos no vinieron de Chaco y de Formosa acá, vinieron a Fuerte Apache primero. Ahi lamentablemente aprendieron conductas non santas entonces era también más difícil ¿viste? tener una relación con ellos, que no se dieran cuenta de que tenian que tener buen comportamiento ya que se los ayudaba" (Norma, asistente social).

La respuesta esperada como agradecimiento es el "buen comportamiento", aquel que cubra las expectativas de la escuela. Estas representaciones construidas alrededor de los habitantes del barrio, son percibidas por los chicos, quienes comúnmente utilizan con ironía expresiones como "a estos tobas no se les puede dar nada". También suelen identificar esa mirada por parte de la escuela; así lo comentaba una de las chicas:

"[En referencia a las maestras y hermanas religiosas, a las que había mencionado previamente]: Se ve así que ellas hablan de eso y miran para acá, [como si pensaran] 'están haciendo mal (...) nosotros les dimos ese terreno y tendrían que estar haciendo lo mismo que nosotros "' (Renata, 17 años).

A su vez, la escuela actualmente alberga a niños de los barrios circundantes. En tanto las condiciones socioeconómicas son bastante compartidas, las relaciones conflictivas con los vecinos se viven en vinculación con ciertos derechos diferenciales a los que accedería el barrio toba en tanto comunidad aborigen. Entre ellos, principalmente, hay que contemplar el propio terreno (“¿cómo viene gente de afuera?”) y la eximición del pago de la matrícula (únicamente en los primeros tiempos). Otros excedían el marco escolar y sus dones, pero contribuían del mismo modo a tensionar las relaciones, como por ejemplo el haber conseguido que la municipalidad asfaltara (años después de lo prometido) la calle que llega desde la ruta y cubre sólo las ocho viviendas de la primera de las hileras del barrio, sin continuar hacia los barrios vecinos.

Por otro lado, veíamos que la asistente social sostenía que "la gente que vivía acá en los barrios se empezó a sentir mal" y que finalmente la congregación cedió los terrenos para construir un nuevo barrio, lo que generó mucho malestar en el barrio toba, ya que se consideraba que ese espacio se convertiría en una futura ampliación del barrio. De hecho, los jóvenes que comienzan "a juntarse" y tener hijos, reclaman a sus mayores por "no haber defendido esas tierras".

También se reflejaba en el fragmento anterior que antes de la conformación del barrio, estas familias se hallaban dispersas en distintos asentamientos marginales de la Ciudad de Buenos Aires y del conurbano bonaerense. Allí nacieron muchos de los niños, niñas y jóvenes que viven en el barrio. Hoy en día se establecen diferenciaciones entre "los que viven en el barrio" y "los que viven en el Chaco": la experiencia de vida -previa a la conformación del barrio- en zonas carenciadas o "villas" de la ciudad dejó sus marcas en las representaciones que los otros construyen sobre los habitantes del barrio 
(Hecht, 2010). En este sentido, y haciendo hincapié en la impronta del espacio escolar en tanto ámbito de interpelación identitaria hacia los niños y niñas, es importante advertir que en la escuela se apela simultáneamente a imágenes contrapuestas sobre "los tobas" sostenidas en una subyacente asociación entre la aboriginalidad y la vida rural "tradicional": una, la que haría referencia a los "auténticos", los que vivieron en el Chaco (y, por ende, son "más lejanos") y la otra, que incluiría a todos los que pasaron por los asentamientos marginales en Buenos Aires:

"Y creo que mi conclusión no es que sean unos vagos, no es que no quieren, pero creo que están muy dañados, creo que es una comunidad muy lastimada, la verdad es que creo que todo este desarraigo y todo este traspaso de villa en villa, creo que hizo que perdieran mucho de lo que es su cultura y de lo que tiene que ver con sus elecciones, por ahí, o con sus parámetros. Me parece que eso está, lo vi como muy devastado y como que no se sabía bien quiénes eran, o sea no tenían esto de la identidad, del indio toba..." (Silvina, integrante del Equipo de Orientación Escolar)

Así, en múltiples ocasiones, en sus trayectorias escolares, los niños y niñas de diversas comunidades tobas son muchas veces señalados negativamente por sus identificaciones étnicas (Hecht, 2010; Bigot, 2010; Borton et al 2010) y, simultáneamente se ven interpelados como portadores de una identidad que, en una comparación prácticamente omnipresente con los "verdaderos indios del Chaco", aparece devaluada.

En esta compleja trama de relaciones sociales, el campo religioso pareciera proveer elementos que materializan y complejizan estas históricas y actuales disputas. Si, tal como señala Ceriani Cernadas, para los grupos tobas, “... los católicos representaban la otredad absoluta y la visión sobre éstos aparecía dialécticamente atravesada por la dimensión étnica (el Evangelio es qom, el catolicismo es doqshi) y la teología y moral de raíz protestante (los católicos "chupan", "fuman" y "son idólatras", entre otros asuntos)" (Ceriani Cernadas, 2008: 253), en el barrio es posible encontrar esta contraposición:

"Vos vas a la iglesia [del Evangelio] y no podés salir a bailar, o a tomar y esas cosas (...) Y acá en la escuela [católica] es diferente, vos sos católico pero igual salís a bailar, salís a tomar y todo eso" (Laura, 14 años)

"Nosotros adoramos a Jesucristo vivo, no a imágenes como los católicos; a Cristo en la época de los milagros (...) los católicos son idólatras" (Pastora Mirta, 54 años).

De este modo, situar en este campo los rumores que dieron comienzo a estas líneas de indagación, nos permite ver que el campo de lo religioso no puede ser comprendido independientemente de su articulación con la vida social, en donde el poder es siempre crucial, por lo que el estatus de autoridad de las prácticas y aseveraciones religiosas debe ser explicado como producto de fuerzas históricas (Asad, 1993).

\section{4) Comentarios finales}

Sostuvimos que la participación en las diversas experiencias formativas -aun si son consideradas como "no obligatorias" para los niños y niñas- contribuye con el proceso de construcción de la creencia (Toren, 2003). De este modo, situamos al rumor acerca 
de las apariciones dentro del marco de las experiencias de los niños y niñas del barrio que los vinculan con las prácticas cotidianas del Evangelio, como la oración.

Ahora bien, no se trataría de un proceso instantáneo por el cual con la sola participación en prácticas religiosas, las personas se conviertan en creyentes, identificándose, por ejemplo, con el Evangelio, ya que, en efecto, los niños del barrio también participan de una gran cantidad de prácticas religiosas en la escuela católica a la que asisten. Si tenemos que en cuenta que lo que el sujeto asimila son situaciones en las cuales los objetos sociales desempeñan determinados papeles y no otros, es necesario analizar cómo son presentados estos a los niños y qué se espera que hagan los niños con ellos. Entonces, el proceso de construir una creencia no se trataría simplemente de "estar ahí", sino que esa participación está mediada no sólo por la agencia de cada sujeto, sino también por diversos mandatos y apelaciones a sentirse identificados con determinados grupos y no con otros (en términos muy generales, "los tobas somos evangelio", desde el barrio; "los tobas no son católicos", desde la escuela). Así, cuando nuestro objetivo es el estudio de las experiencias formativas de los niños y niñas, cobra importancia el rol que cumplen las significaciones sociales preexistentes. Entre ellas, en nuestro caso particular, debemos citar todos los sentidos que socialmente fueron construyéndose alrededor de la figura del católico, algunos de los cuales hemos mencionado; y aquí cabe subrayar nuevamente la potencialidad de los rumores, al otorgar consentimiento y credibilidad a determinadas afirmaciones. Aún cuando las tensiones entre la escuela y las familias excede las disputas en el campo religioso, ya que su marco está dado por una compleja disputa que entreteje los posicionamientos en la estructura social de clases con un histórico conflicto interétnico, considero que la religión deviene una arena en la que se conjugan ( $\mathrm{y}$ no necesariamente donde se dirimen) estas confrontaciones. Esto nos permite resituar al rumor y su potencialidad, ya que estos mecanismos, como he mencionado, forman parte de las experiencias formativas de los niños y niñas del barrio.

\section{Bibliografía}

ACHILLI, E. (1996): Práctica docente y diversidad sociocultural - Homo Sapiens Rosario.

ASAD, T. (1993): Genealogies of religion - Johns Hopkins University Press Baltimore.

BARLEY, N. (2000): Bailando sobre la tumba - Editorial Anagrama - Barcelona.

BARTOLOMÉ, L. (1971): "Política y redes sociales en una comunidad urbana de indígenas Toba: un análisis de liderazgo y "brokerage"” - Anuario Indigenista - Vol. XXXI, México (págs 77-97).

BIGOT, M. (2010): "Discriminación indígena: Los indígenas qom de los Pumitas" Papeles de Trabajo - Centro de Estudios Interdisciplinarios de Etnolingüística y Antropología Sociocultural 19 - Universidad Nacional de Rosario - Rosario (págs. 113)

BIGOT, M.; G. RODRÍGUEZ y H. VAZQUEZ (1992): "Los asentamientos tobas en la ciudad de Rosario" en La problemática indígena. Estudios antropológicos sobre pueblos indígenas de la Argentina - RADOVICH, J. C. y BALAZOTE, A. (COMP) Centro Editor de América Latina. Buenos Aires. 
BORTON, L.; ENRIZ, N.; GARCÍA PALACIOS, M. y HECHT, A. C. (2010): "Una aproximación a las representaciones escolares sobre el niño indígena como sujeto de aprendizaje" en La Educación Intercultural Bilingüe en Argentina: Análisis antropológicos de experiencias en comunidades indígenas - HIRSCH, S. y SERRUDO, A. (COMP) - Ed. Biblos. Buenos Aires.

BOURDIEU, P. (2010): El sentido práctico - Siglo XXI editores - Buenos Aires.

CERIANI CERNADAS, C. (2008): Nuestros Hermanos Lamanitas: Indios y fronteras de la imaginación mormona - Editorial Biblos - Buenos Aires.

CERIANI CERNADAS, C. y S. CITRO (2005): "El movimiento del evangelio entre los Toba del Chaco argentino. Una revisión histórica y etnográfica" en De Indio a Hermano. Pentecostalismo indígena en América Latina - GUERRERO, B. et al (COMP) - Ed. Campus. Chile.

CITRO, S. (2009): Cuerpos Significantes. Travesías de una etnografía dialéctica Biblos - Buenos Aires.

COLANGELO, A. (2009): "La salud infantil en contextos de diversidad sociocultural" en Pueblos indigenas. Interculturalidad, colonialidad, politica - TAMAGNO, L. (COORD) - Biblos. Buenos Aires.

FASANO, P. (2006): De boca en boca. El chisme en la trama social de la pobreza Antropofagia - Buenos Aires.

GARCÍA PALACIOS, M. (2012): Religión y etnicidad en la experiencias formativas de los niños y niñas de un barrio toba de Buenos Aires. Tesis de Doctorado, Mimeo. Buenos Aires: Programa de Doctorado de la Facultad de Filosofía y Letras, UBA.

HECHT, A. C. (2010): 'Todavía no se hallaron hablar en idioma'. Procesos de socialización lingüistica de los niños en el barrio toba de Derqui (Argentina) - Lincom - Alemania.

HIRSCHFELD, L. (2002): "Why don't anthropologist like children?" - American Anthropologist - N. 2, Vol. 104- USA (págs 611-627).

MILLER, E. (1979): Los tobas argentinos. Armonía y Disonancia en una sociedad Siglo XXI - México.

PIRES, F. (2007): Quem tem medo de mal-assombro? Religiao e Infancia no semi-árido nordestino. Tesis de Doctorado, Mimeo. Río de Janeiro: Programa de Postgraduación UFRJ, Brasil.

ROCKWELL, E. (1995): "De huellas, bardas y veredas: una historia cotidiana en la escuela" en La escuela cotidiana - ROCKWELL, E. (COORD) - Fondo de Cultura Económica. México.

SANTILLÁN, L. (2009): "Prácticas cotidianas e intersecciones entre la Iglesia Católica y grupos familiares en asentamientos populares del Gran Buenos Aires" - Revista Cadernos de Campo - N 17 - Universidad de Sao Paulo.

SEGATO, R. (2007): La Nación y sus Otros. Raza, etnicidad y diversidad religiosa em tiempos de Políticas de Identidad - Prometeo - Buenos Aires.

SEGATO, R. (2005): "Cambio religioso y desetnificación: La expansión evangélica en los Andes Centrales de Argentina" en De Indio a Hermano. Pentecostalismo indígena en América Latina - GUERRERO, B. et al (COMP) - Ediciones Campus. Chile.

SPENNEMANN, I. (2006): Migración y proceso político identitario: La comunidad indígena Q'om Davixaiqui de Provincia de Buenos Aires. Tesis de Licenciatura, Mimeo. Buenos Aires: Licenciatura en Antropología, UBA. 
STEPHENS, S. (1995): "Children and the politics of culture in 'late capitalism"” en Children and the Politics of Culture - STEPHENS, S. (ED.) - Princeton University Press. Princeton.

TAMAGNO, L. (2001): Nam qom hueta'a na doqshi lma'. Los tobas en la casa del hombre blanco. Identidad, memoria y utopía - Ediciones Al Margen - La Plata.

TASSINARI, A. (2007): “Concepçoes indígenas de infancia no Brasil” - Tellus - 13 (7) - Brasil (págs 11-25).

THOMAS, L-V. (1991): La Muerte. Un estudio cultural - Ediciones Piados Barcelona.

TOLA, F. (2007): “'Eu nao estou só(mente) em meu corpo'. A pessoa e o corpo entre os toba (qom) do chaco argentino" - Mana - 13 (2) - Brasil (págs 499-519).

TOLA, F. (2006): “'Después de muerto hay que disfrutar, en la tierra o en el mundo celestial'. Concepciones de la muerte entre los toba (qom) del Chaco argentino" Alteridades - 16 (32) - (págs 153-164).

TOLA, F. (1999): "Fluidos corporales y roles paternos en el proceso de gestación entre los tobas orientales (qom) de la provincia de Formosa" - Papeles de Trabajo - Centro de Estudios Interdisciplinarios de Etnolingüística y Antropología 8 - Universidad Nacional de Rosario - Rosario (págs. 197-221).

TOREN, C. (2003): "Becoming a Christian in Fiji: an ethnographic study of ontogeny" - Journal of the Royal Anthropological Intitute - 10 - (págs 709-727).

WRIGHT, P. (2008): Ser en el sueño. Crónicas de historia y vida toba - Editorial Biblos - Buenos Aires.

WRIGHT, P. (1999): "Histories of Buenos Aires" en Peoples of the Gran Chaco. Native Peoples of the Americas - MILLER, E. (ED) - Bergin \& Garvey. USA.

ZAPATA, L. (2005): La mano que acaricia la pobreza. Etnografía del voluntariado católico - Antropofagia - Buenos Aires. 